Article

\title{
Investigation of the Possibilities to Improve Hydrodynamic Performances of Micro-Hydrokinetic Turbines
}

\author{
Marina Barbarić * and Zvonimir Guzović \\ Department of Energy, Power and Environmental Engineering, Faculty of Mechanical Engineering and Naval \\ Architecture, University of Zagreb, Ivana Lučića 5, p.p. 102, 10002 Zagreb, Croatia; zvonimir.guzovic@fsb.hr \\ * Correspondence: marina.barbaric@fsb.hr
}

Received: 23 July 2020; Accepted: 31 August 2020; Published: 2 September 2020

check for updates

\begin{abstract}
Horizontal axis turbines are commonly used for harnessing renewable hydrokinetic energy, contained in marine and river currents. In order to encourage the expansion of electricity generation using micro-hydrokinetic turbines, several design improvements are investigated. Firstly, optimization-based design of rotor blade is used to get as close as possible to the efficiency limit of $59.3 \%$ (known as Betz limit), that counts for bare turbine rotors, placed in the free flow. Additional diffuser elements are further added to examine the potential to overcome the theoretical efficiency limit by accelerating water at the axial direction. Various diffuser geometrical configurations are investigated using the computational fluid dynamics (CFD) to obtain insight into hydrodynamics of augmented micro-hydrokinetic turbines. Moreover, the turbines are compared from the energy conversion efficiency point of view. The highest maximum power coefficient increase of $81 \%$ is obtained with brimmed (flanged) diffuser. Diffusers with foil-shaped cross-sections have also been analyzed but power augmentation is not significantly greater than in the case of simple cross-section designs of the same dimensions. The power coefficients' comparison indicate that considerable power augmentation is achievable using brimmed diffuser with higher value of length-to-diameter ratio. However, the impact of diffuser length increase on the power coefficient enhancement becomes weaker as the length-to-diameter ratio reaches a value of 1 .
\end{abstract}

Keywords: hydropower; hydrokinetic turbine; shrouded turbine; diffuser augmented turbine; optimization based design; power augmentation

\section{Introduction}

Hydrokinetic technology has gained increased attention as an alternative for renewable energy production, especially at locations where conventional hydropower technology cannot provide a feasible solution. The main compelling aspect of the technology is generation predictability, which means that unlike many other renewable sources, data on the expected generation in the next few days or even weeks, are quite accurate and reliable. However, the main barrier to wider commercialization is relatively low efficiency, limited by so-called Betz limit, which indicates that hydrokinetic turbines cannot capture more than $59.3 \%$ of energy in open flow, regardless of the turbine design. In addition, water depth at location also limits generated power that is usually rather small. That is particularly true for the small hydrokinetic turbines for river application. To approach the problem of relatively low efficiency, the concept of ducted or diffuser-augmented turbines can be used. These elements serve as turbine casing that causes pressure drop behind the turbine and accelerate the water in axial direction. As a consequence, more power can be extracted by the turbine. Most of the available literature on diffuser-augmented turbine is related to the wind turbine rotors. Flow field analysis 
using two-dimensional CFD (computational fluid dynamics) was performed in [1] to investigate the influence of diffuser flange's angle on velocity at wind turbine diffuser entrance. Flow simulations of urban wind turbine system presented in [2] show that power-augmented shroud can improve the low efficiency problem of vertical axis turbine. A considerable increase in the generated power of horizontal axis wind turbines were obtained with different shroud geometries in [3]. Experimental investigations of wind turbine systems presented in [4] also show that shrouding turbine can remarkably increase power coefficient. In addition, the obtained results indicate the potential in using twin rotor (which are usually Counter-Rotating Open Rotor devices) at small separation distances between rotor rotation planes. Mathematical modeling of shroud wind turbine is proposed in [5], together with new equations to predict the power coefficient and speed-up ratio effects. Computational fluid dynamics analysis of shrouded wind turbine, presented in [6], show a considerable increase of the power coefficient compared to unshrouded turbine. According to [7], the use of semi-opened duct in higher ranges of wind speed can exceed the conventional shrouds in power and rotor speeds. The optimization procedure, based on classical blade element theory, for design of the blades of a diffuser-augmented wind turbine is presented in [8]. A mathematical model describing the internal velocity for three conical diffusers is presented in [9]. The comparison of results of numerical and experimental investigations of three different horizontal axis turbines, presented in [10], strongly suggest that accurate predictions of horizontal axis turbine blade performance at full-scale conditions are possible using the CFD method.

There are also some published numerical and experimental studies on the flow characteristic of hydrokinetic turbines. Design method of horizontal axis hydrokinetic river turbine without diffuser is proposed in [11], while hydrodynamic performance prediction of bare rotor marine current turbines using Blade Element Momentum (BEM) method is performed in [12]. Blade design method presented in [13] can be used to enhance blade reliability with relatively high efficiency for energy generation. Tidal stream turbine performances are investigated numerically and experimentally in [14]. The investigation presented in [15] indicate that there is a limit to available tidal current power output (TCP) due to significant reduction in tidal currents. It is founded that the installation of turbines not only slowed down tidal currents but also affected a certain area near the TCP extraction site. The results of a study of large-scale tidal current power array and ocean response, presented in [16], show that currents are decelerated significantly downstream of the array.

To approach the problem of low-efficiency, Savonius turbine with a variable geometry of blades is proposed in [17]. A methodology for modeling shrouded horizontal axis hydrokinetic turbine, based on the classical design method for the Kaplan turbine concept, with some additional parameters to take into account the zero-head conditions, is presented in [18]. The analytical model for ducted turbines coupled with numerical methods is presented in [19]. The ducted Blade Element Momentum Theory model is applied to a bi-directional ducted tidal turbine in [20] to benefit from significantly lower computational requirements when compared to the RANS-BEM approach. The BEM model is adopted for the design of diffuser-augmented hydro turbines in [21] by inserting the effect of diffuser efficiency into the BEM model. The empirical model for ducted tidal turbine performance presented in [22] is based on CFD results, but applicable to simple turbine concepts. CFD method has also been used in [23] to understand interaction between rotor and diffuser for the efficient design of augmented hydrokinetic turbine. It is observed that the interaction term has significant effect on the system performances, but the authors stated that further study is required for better understanding of this aspect. Numerical calculation based on the CFD method is used in [24] for calculation of hydrodynamic loads of a horizontal turbine under wave-flow condition.

The results of numerical and experimental analysis, presented in [25], show strong impact of diffuser shape design and its interaction with the rotor on the hydrodynamic performances. In order to avoid cavitation inception on diffuser-augmented hydrokinetic blades, the design method proposed in [26] extends optimization of the augmented wind turbine blades, presented in [8], to hydrokinetic case. The experimental investigation of wake recovery characteristics of diffuser- augmented tidal stream turbine question their applicability for array deployment due to relatively low wake recovery 
rate, as stated in [27]. The wake interaction of bare marine hydrokinetic turbines was studied in [28]. Investigation results indicate power coefficient decrease for downstream turbine due to high turbulent intensity caused by the upstream turbine. The relationship between power extraction and the layout of tidal current turbine arrays was investigated in [29]. A RANS-implemented BEM code has been applied in [30] to analyze the performances of bare, ducted and open-center turbines. The numerical algorithm for performances calculation of ducted axial-flow hydrokinetic turbines, based on the vortex-lattice method is compared with experimental measurements in [31]. Quite large discrepancies were observed for extreme tip to speed ratio values. The results of both numerical and experimental investigations of small-scale hydrokinetic turbine presented in [32], show hydrokinetic turbine performance degradation at low inlet velocities. This indicates that turbine design with diffuser is even more favorable at relatively low velocities, where viscous and dissipative effects are significant. Performed numerical investigations of diffuser-augmented hydrokinetic turbine, presented in [33], indicate the necessity of diffuser shape optimization. According to [34] optimization strategies are used in turbomachinery design to accomplish several requirements that assume more efficient, quieter and more environmentally friendly technology designed at low cost and short time scales.

Following on the research review above, there is no comprehensive comparison of different diffuser configurations of small-scaled horizontal axis turbines for river and marine current applications. Moreover, most of the available studies deal with large-scale turbines, and small or micro-scaled technologies, especially those for the river application, have rarely been reported so far. Computational fluid dynamic methods were employed to obtain an insight into hydrodynamics of hydrokinetic turbines with different diffuser configurations. The results of this work can be used in pre-design phase allowing the designer to select the most effective diffuser configuration for the specific case. The results of a series of three-dimensional CFD simulations of bare turbine design gives relatively high power coefficient even without diffuser augmentation, which confirms the effectiveness of optimization-based rotor design method presented in this work. The research results presented in this paper can be used for hydrodynamic design of highly efficient horizontal axis turbines for river or marine current applications. In addition, the results can be used as input for further research on performance improvements of diffuser-augmented micro-hydrokinetic turbines.

\section{Methods}

\subsection{Rotor Design}

Rotor design of lift-based axial-flow turbines is usually based on the Blade Element Momentum (BEM) theory that combines the momentum theory and the blade element theory to relate blade shape and rotor ability to extract power from the fluid [35]. The same theory is commonly used in the wind turbine blade design. When the mentioned theory is combined with advanced computing algorithms, design can be accelerated and improved [34]. An additional phenomenon that should be taken into account when designing hydrokinetic turbine rotor is a possible occurrence of cavitation. When cavitation inception is avoided, a mathematical model based on BEM theory can be used for prediction of hydrokinetic turbine performance as well as for the determination of optimal chord length and pitch angle. In this paper, an integrated, optimization-based design method is proposed. The flow chart of integrated approach presented in Figure 1 is relatively fast and applicable to a comprehensive range of hydrokinetic turbines, with minimal modification in the model, as will be described below. The output of the optimization model is a hydro-dynamically-shaped turbine blade that can be converted into a series of splines, which is beneficial for later CFD analysis or Computer Numerical Control (CNC) manufacturing. 


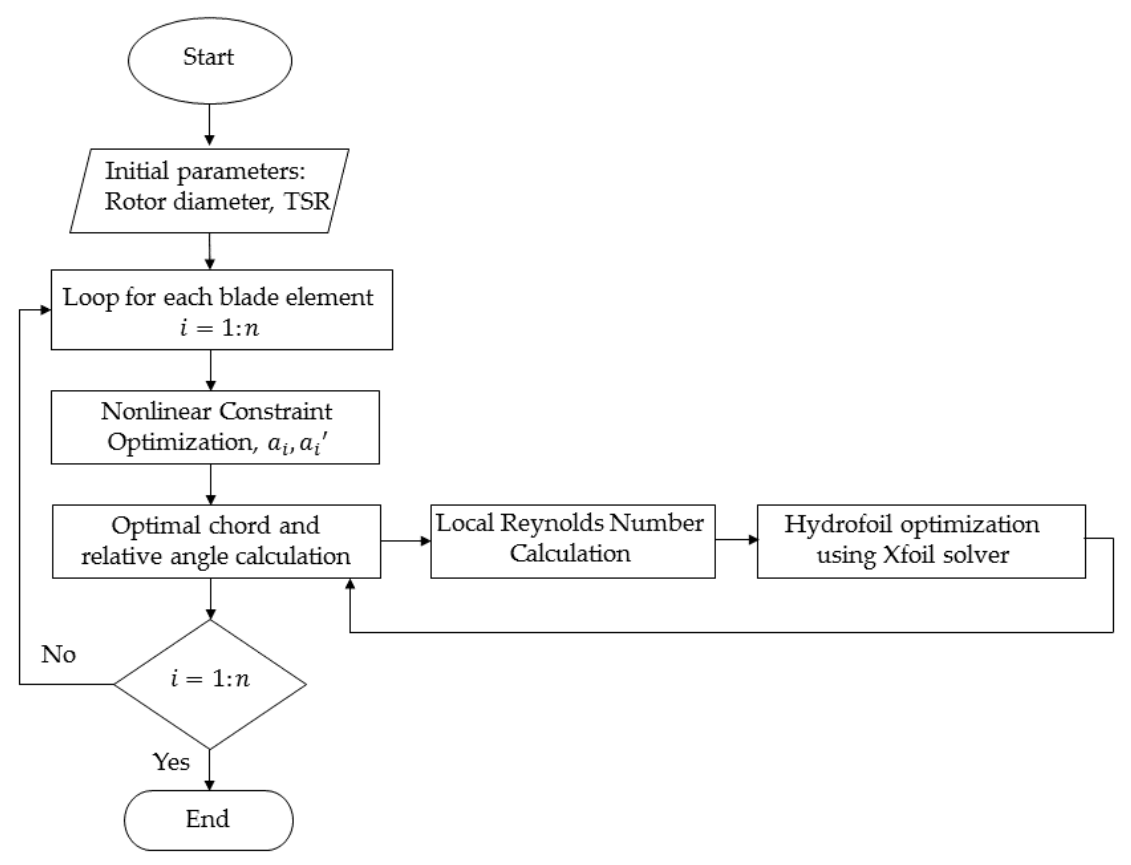

Figure 1. Rotor design flow chart.

The initial step, when designing hydrokinetic turbine blades, is determination of parameters that primarily depend on the chosen location for the installation. In this work, location at the Croatian river, Drava, is considered for the micro-hydrokinetic turbine installation. Due to water depth limitation at the chosen location, the rotor diameter is selected to be $2 \mathrm{~m}$. Hub diameter equals $20 \%$ of the turbine diameter, as recommended in [36]. Another very important parameter that should be pre-defined is tip to speed ratio (TSR), which is defined as follows:

$$
T S R=\frac{\omega \times R}{v_{\infty}}=\frac{u}{v_{\infty}}
$$

The lower tip to speed ratio requires higher chord lengths and thus, more material. In addition, a quite variable chord distribution is required for lower TSR which is not preferable from the manufacturing point of view. On the other hand, lower TSR and higher blade pitch are desirable for structural stability of turbine. The operational TSR is chosen as 4 in order to meet structural criteria and ensure ease of fabrication [36]. To find optimal chord distribution and blade pitch angle distribution along the blade span, an integrated design optimization approach is used and hydrofoil geometry optimization is incorporated in the algorithm as shown in Figure 1.

To perform the optimization, BEM model is reformulated in the form of the objective function and nonlinear constraint. Maximum power coefficient is obtained by searching for the optimal values of sectional induction factors $a$ and $a^{\prime}$ using genetic algorithm. The Equation (2) represents objective function while Equation (3) shows nonlinear constraint:

$$
\begin{gathered}
\min f=-C_{p}=-\frac{8}{\lambda^{2}} \int_{\lambda_{h}}^{T S R} F \lambda_{r}^{3} a^{\prime}(1-a)\left[1-\left(C_{D} / C_{L}\right) \cot \varphi d \lambda_{r}\right] \\
a^{\prime}\left(a^{\prime}+1\right) \lambda_{r}{ }^{2}=a(1-a) F
\end{gathered}
$$

The original BEM theory of Betz and Glauert is extended with additional correction factor in order to take into account the effects of tip and hub losses. The fluid flow around the tip, from lower to upper surface, caused by the lower pressure on suction side than on the pressure side of blade, reduces 
lift and causes decreased power production near the blade tip. This effect is taken into account by Prandtl's tip loss correction factor, which affects the forces derived from momentum theory, as follows:

$$
F_{t}=\left(\frac{2}{\pi}\right) \cos ^{-1}\left[\exp \left(-\left\{\frac{(B / 2[1-(r / R)])}{(r / R) \sin \varphi}\right\}\right)\right]
$$

The swirling flow due to presence of hub also causes losses, which are taken into consideration as well by including the hub loss correction factor, given by Equation (5):

$$
\begin{gathered}
F_{h}=\left(\frac{2}{\pi}\right) \cos ^{-1}\left[\exp \left(\frac{\left(B / 2\left(r_{h}-r\right)\right)}{r \sin \varphi}\right)\right] \\
F=F_{t} F_{h}
\end{gathered}
$$

The overall correction factor is calculated by using Equation (6) and introduced in the expressions given by Equation (2). Power coefficient, $C_{p}$ given by Equation (7) is one of the main parameters for the fluid-dynamic evaluation of rotors [23], together with thrust coefficient $C_{T}$ which is given by Equation (8).

$$
\begin{aligned}
C_{p} & =\frac{P}{\frac{1}{2} \times \rho \times A \times v_{\infty}^{3}} \\
C_{T} & =\frac{T}{\frac{1}{2} \times \rho \times A \times v_{\infty}^{2}}
\end{aligned}
$$

The inputs required for the initial BEM iteration (lift and drag coefficients of the initial foil) are obtained from Xfoil [37]. After determination of the axial and angular induction factors, optimal relative angle is obtained by using Equation (9):

$$
\varphi(r)=\tan ^{-1}\left[\frac{1-a}{\left(1+a^{\prime}\right) \lambda_{r}}\right]
$$

Finally, chord and twist angle are calculated by using Equations (10) and (11), respectively:

$$
\begin{gathered}
\theta_{p}(r)=\varphi(r)-\alpha \\
c(r)=\frac{8 \pi a F r(1-a F) \sin ^{2} \varphi(r)}{B(1-a)^{2}\left(C_{L} \cos \varphi(r)+C_{D} \sin \varphi(r)\right)}
\end{gathered}
$$

Hydrodynamic performances are highly influenced by the characteristics of the selected hydrofoil. Rather than using hydrofoils from the small set of ones that are designed especially for the hydrokinetic turbines, a new hydrofoil with high lift-to-drag ratio and delayed cavitation inception was designed by using genetic algorithm.

The possibility of cavitation occurrence is a very important factor that should be taken into account when designing hydrofoils for hydrokinetic turbines. In addition, when compared to wind turbine, hydrokinetic turbine blades experience larger thrust forces due to the fact that water is more than 800 times denser than air. Using optimization techniques in the hydrofoil design procedure can remarkably enhance lift-to-drag ratio. Preliminary results presented in [38] show that increase in the lift-to-drag ratio of foil can be up to $30 \%$. In general, the optimization process requires mathematical description of the hydrofoil shape. Most commonly, hydrofoils are represented by a quite large number of coordinate points. Using such a representation can be beneficial in terms of a wide variety of different geometries that can be obtained. However, the problem is high computation cost in consequence of the large number of design (control) variables included in the optimization process. Computational efficiency can be increased by using parametrization methods such as polynomial or spline representation of hydrofoils that substantially reduces the number of points needed to easily 
reshape hydrofoil geometry. The non-uniform rational B-splines (NURBS) representation is used in this work as it can effectively represent a wide variety of different shapes with a relatively small number of parameters which makes the optimization computationally effective. More detailed explanation on hydrofoil creation using two different NURBS curves is presented in [39]. Hydrofoil is finally generated by using a total of 12 control points which are fixed in $\mathrm{x}$-direction but free to move in $\mathrm{y}$-direction as can be seen in Figure 2.

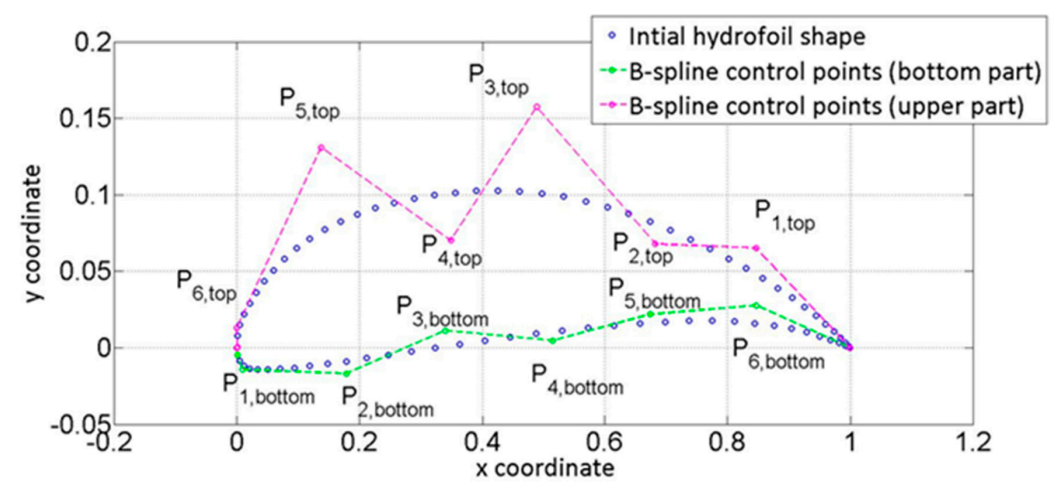

Figure 2. Decision variables for hydrofoil shape optimization (control points).

To avoid cavitation inception, minimum coefficient of pressure has to be greater than the cavitation number. As the design requirements include multiple objectives, weighting factors are used to formulate the single objective function for optimization.

The objective function, given by Equation (12), is formulated to find a hydrofoil with high lift coefficient (higher than the reference one), low coefficient of drag, and delayed cavitation inception at angles of attack close to the design one. Minimum pressure coefficient, $K_{p, \min }$ in Equation (12) is minimum of pressure coefficient $K_{p}$ that is defined by Equation (13):

$$
\begin{gathered}
\min f=\sum_{i=2}^{12} w_{1, \alpha=i} \times \frac{1}{C_{L, \alpha=i}}+\sum_{i=3}^{12} w_{2, \alpha=i} \times C_{D, \alpha=i}+\sum_{i=7}^{12} w_{3, \alpha=i} \times\left|K_{p, \min , \alpha=i}\right| \\
K_{p}=\frac{p-p_{a t m}}{0.5 \times \rho \times w^{2}}
\end{gathered}
$$

In order to avoid cavitation inception, negative minimum pressure coefficient, $K_{p \text {,min }}$ should be less than or equal to cavitation number [40], $\sigma$, defined as follows:

$$
\sigma=\frac{p_{\mathrm{atm}}+\rho \times g \times H-p_{\mathrm{v}}}{0.5 \times \rho \times w^{2}}
$$

The weighting factors $w_{1, \alpha=i}=10, w_{2, \alpha=i}=20$ and $w_{3, \alpha=i}=5$ were utilized to formulate multiple objective optimization problem by using single objective function. Weighting factors can be changed depending on the importance of individual design parameter in objective function. After obtaining optimized foil design, new chord and blade twist distributions were calculated using updated data on lift-and-drag coefficient and results are shown in Figure 3. 


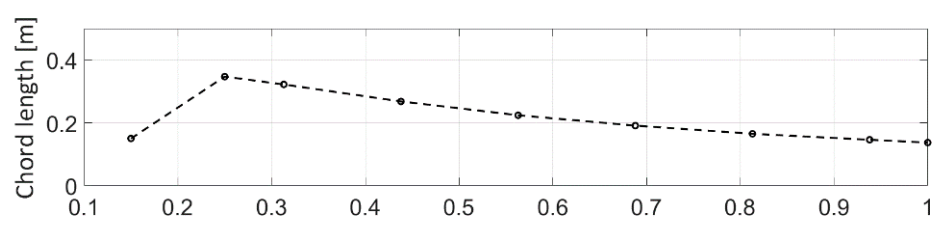

(a)

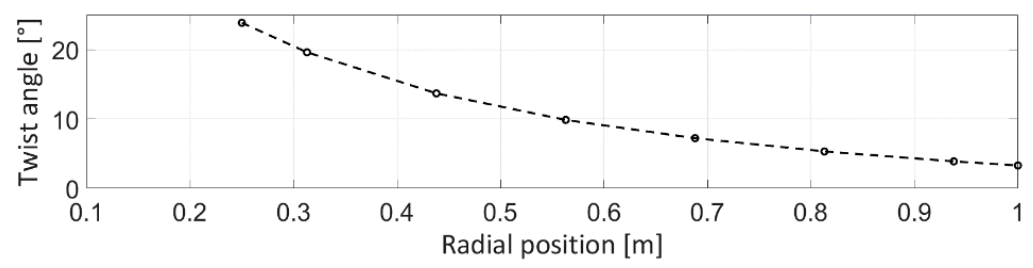

(b)

Figure 3. (a) Chord and (b) twist angle distribution.

\subsection{Diffuser Design}

Various turbine designs with diffusers were considered to investigate the potential of overcoming the theoretical efficiency limit that equals $59.3 \%$ and counts for bare turbine rotors in open flow. In order to get insight into hydrodynamic characteristics and conclude on the optimal configuration for the specific application, different geometries and types of diffusers were taken into consideration. The remarkable output power increase can be attained, even with slight increase in the water velocity at rotor plane, as power is proportional to the cube of the water velocity.

The first considered configuration, DF, shown in Figure $4 \mathrm{a}$, is a simple diffuser. The rotor is placed close to the diffuser entrance to avoid the flow caused by boundary layer separation on the inner surface. To examine the influence of the brim on the velocity profiles, a diffuser named DFB shown in Figure $4 \mathrm{~b}$, has been considered. The brim produces a low-pressure region behind the rotor and causes vortex generation which is expected to increase mass flow rate through diffuser. Diffuser with cross-section shaped as inverted foil (NACA 4412) is presented in Figure 4c and named DFN. The influence of the main design parameters on the energy conversion efficiency have been examined by varying diffuser length, $L$ and open (expansion) angle, $\beta$ as presented in Table 1 .
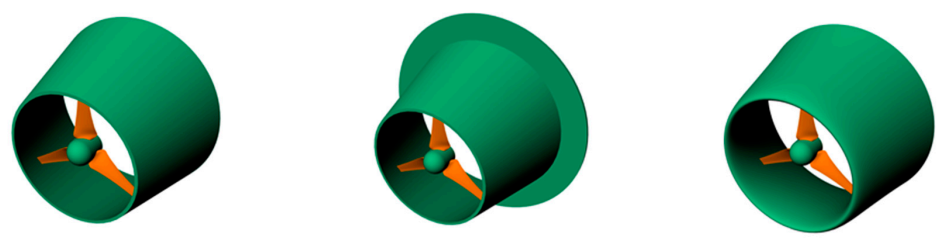

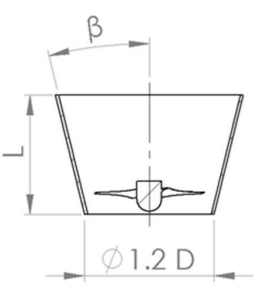

(a)

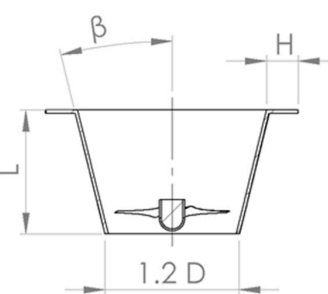

(b)

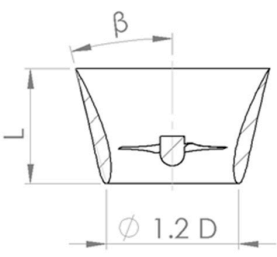

(c)

Figure 4. Representation of diffusers' geometrical configurations: (a) Diffuser configuration DF; (b) Diffuser configuration DFB; (c) Diffuser configuration DFN. 
Table 1. Design parameters of diffusers.

\begin{tabular}{cccc}
\hline Type & $\boldsymbol{L}(\mathbf{m})$ & $\left.\boldsymbol{\beta} \mathbf{(}^{\circ}\right)$ & H/D \\
\hline DF-1 & $0.75 \mathrm{D}$ & 5 & - \\
DF-2 & $0.75 \mathrm{D}$ & 10 & - \\
DF-3 & $0.75 \mathrm{D}$ & 15 & - \\
DF-4 & 1D & 15 & - \\
DF-5 & $1.25 \mathrm{D}$ & 15 & - \\
DFB-1 & $0.75 \mathrm{D}$ & 15 & 0.25 \\
DFB-2 & 1D & 15 & 0.25 \\
DFB-3 & $1.25 \mathrm{D}$ & 15 & 0.25 \\
DFN-1 & 1D & 7 & - \\
DFN-2 & 1D & 10 & - \\
DFN-3 & 1D & 13 & - \\
\hline
\end{tabular}

\subsection{Numerical Methods}

Decomposing incompressible and isothermal Navier-Stokes equations given by (15) and (16) into Reynolds-Averaged Navier-Stokes (RANS) equations make it possible to simulate turbulent flows with decreasing computational power:

$$
\begin{aligned}
\rho \frac{\partial u_{i}}{\partial t}+\rho u_{j} \frac{\partial u_{i}}{\partial x_{j}} & =-\frac{\partial p}{\partial x_{i}}+\mu \frac{\partial^{2} u_{i}}{\partial x_{i} x_{j}} \\
\frac{\partial u_{i}}{\partial x_{i}} & =0
\end{aligned}
$$

For the RANS equations, given by (17) and (18), time-dependent turbulent velocity fluctuation is separated from the mean flow velocity. Other than the velocity, other flow properties can also be decomposed into its mean and fluctuating parts. A more detailed explanation of RANS equations for turbulence modeling can be found in [41].

$$
\begin{gathered}
\frac{\partial \overline{u_{i}}}{\partial t}+\overline{u_{j}} \frac{\partial \overline{u_{i}}}{\partial x_{j}}=-\frac{\partial \bar{p}}{\partial x_{i}}+\mu \frac{\partial^{2} \overline{u_{i}}}{\partial x_{i} x_{j}}-\frac{\partial \overline{u_{i}{ }_{i}^{\prime}{ }_{j}}}{\partial x_{j}} \\
\frac{\partial \overline{u_{i}}}{\partial x_{i}}=0
\end{gathered}
$$

The chosen turbulence model is $k-\omega$ SST, which is one of the most commonly used models. This model include two equations, and variable $k$ determines the energy in turbulence while $\omega$ determines the scale of turbulence. The $k-\omega$ SST uses blending function to gradually transition from the standard $k-\omega$ model near the wall to a high Reynolds-number version of the $k-\varepsilon$ model in the outer portion of the boundary layer.

\subsection{Computational Setup}

Computations were performed using ANSYS FLUENT 18.2 software [42]. The computational domain consists of two domains, one for rotating zone and another for stationary region. The rotating periodic boundary conditions are applied, and thus, the whole domain is one-third of a cylinder with only one blade, as shown in Figure 5. 


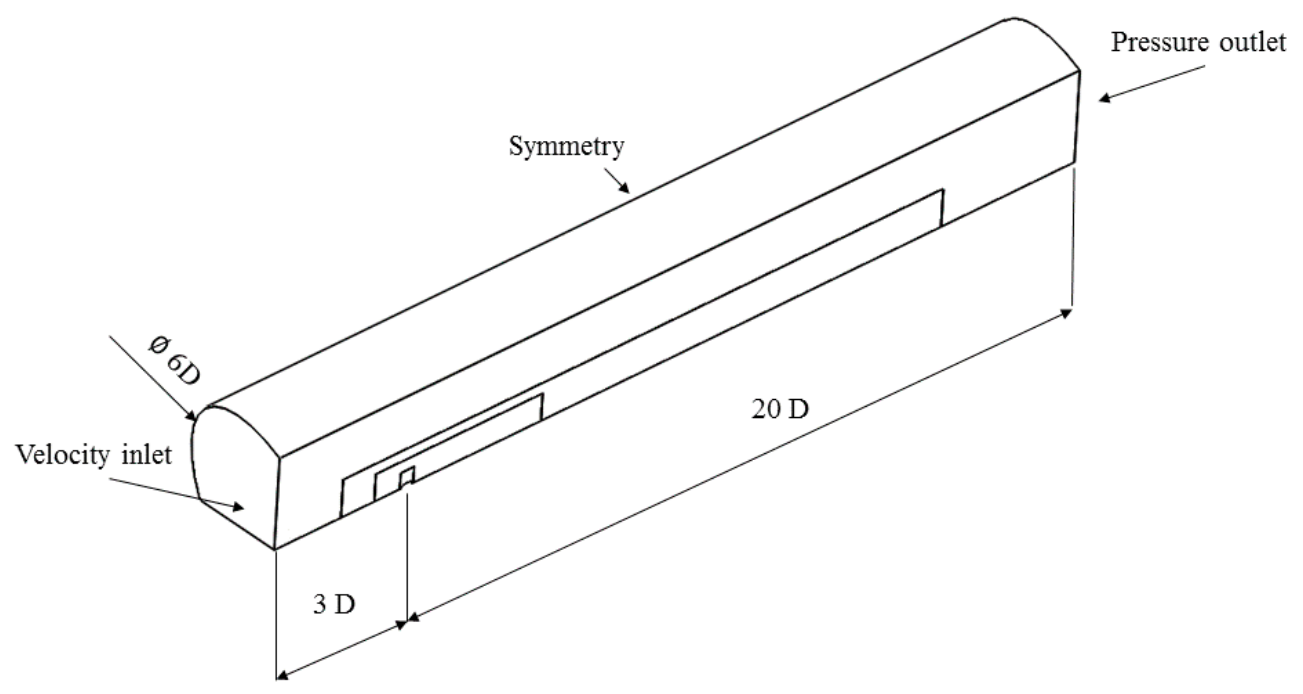

Figure 5. Computational domain.

The Multiple Reference Frame Model (MRF), which is also known as frozen rotor approach, is used to model rotating part. The rotating zone diameter is $5 \%$ larger than the rotor diameter while the rotating zone length equals $25 \%$ of the rotor diameter. The rotating zone dependence is examined by increasing upstream length, downstream length and domain diameter to ensure that the rotating domain size negligibly affects the results. Computational domain upstream and downstream length are determined according to computational domain independence tests available in the literature [25], but the wake zone is also considered, and thus, downstream length is slightly greater than usual. At the inlet, which is located 3D upstream, velocity inlet boundary condition is applied. The symmetry boundary condition is imposed for the outer domain diameter of $6 \mathrm{D}$, while pressure outlet boundary is applied for the outlet, which is located 15D downstream. The turbine and diffusers were configured as non-slip walls. ANSYS Fluent Meshing is used after, to create volume polyhedral mesh.

To perform numerical uncertainty assessment, the forces and momentum generated with three different mesh configurations were calculated at TSR $=6$ for turbine DFB-3. The Grid Convergence Index (GCI) calculation was performed using recommended procedure for estimation of discretization error presented in $[43,44]$. Representative mesh size, $h$ was calculated as follows:

$$
h=\left[\left[\frac{1}{N} \sum_{i=1}^{N}\left(\Delta V_{i}\right)\right]^{1 / 3}\right]
$$

The refinement factors, $r_{i j}$ were calculated based on the representative mesh size.

$$
r_{21}=h_{2} / h_{1} ; r_{32}=h_{3} / h_{2}
$$

Based on practical experience, it is desirable that the grid refinement ratio is greater than 1.3 [45]. The apparent order, $p$ of the method was calculated using the following expressions:

$$
\begin{gathered}
p=\frac{1}{\ln r_{21}}|\ln | \varepsilon_{32} / \varepsilon_{21}|+q(p)| \\
q(p)=\ln \left(\frac{r_{21}^{p}-1}{r_{32}^{p}-1}\right) \\
s=1 \times \operatorname{sgn}\left(\varepsilon_{32} / \varepsilon_{21}\right)
\end{gathered}
$$


In Equations (20) and (22) $\varepsilon_{32}=\phi_{3}-\phi_{2} \varepsilon_{21}=\phi_{2}-\phi_{1}$ where $\phi_{1}, \phi_{2}$ and $\phi_{3}$ are the $C_{\mathrm{P}}$ solutions.

$$
\begin{gathered}
e_{a}^{21}=\left|\frac{\phi_{1}-\phi_{2}}{\phi_{1}}\right| \\
\mathrm{GCI}_{21}=\left|\frac{1.25 e_{a}^{21}}{r_{21}^{p}-1}\right|
\end{gathered}
$$

The results of above procedure of GCI calculation are reported in in Table 2.

Table 2. Numerical uncertainty assessment and GCI (Grid Convergence Index) calculation.

\begin{tabular}{ccccccccc}
\hline Mesh & $\boldsymbol{N}$ & $\boldsymbol{\phi}$ & $\boldsymbol{r}_{i j}$ & $\boldsymbol{\varepsilon}$ & $\varepsilon_{21} / \varepsilon_{32}$ & $\boldsymbol{p}$ & $\boldsymbol{e}_{\boldsymbol{a}}^{21}$ & $\mathrm{GCI}_{21}$ \\
\hline 1 & 2.5 Million & 0.8024 & 1.56 & -0.034 & 0.2764 & & & \\
2 & 1.6 Million & 0.8147 & 2.03 & -0.0123 & monotonic & 1.48 & $0.4 \%$ & $0.63 \%$ \\
3 & 0.8 Million & 0.8181 & - & - & convergence & & & \\
\hline
\end{tabular}

The GCI shows an error band on how far the solution is from the asymptotic value. It also indicates how much the solution would change with further refinement [46]. The solution shows good mesh convergence with GCI value of $0.63 \%$.

The refinement zones were used to reduce the overall number of cells as large computational domain is required to capture wake, as shown in Figure 6. The near wake refinement zone, with an average cell size of $100 \mathrm{~mm}$, ranges from the rotor plane to 3D downstream, where relative pressure is expected to become near zero. Inside near wake refinement zone, there was one additional refinement level close to turbine with 2D in length and 1.5D in diameter. The far wake zone length was set to $12 \mathrm{D}$ as this is expected length required for the free stream velocity recovery. The refinement zones with different cell sizes were merged in ANSYS Fluent using feature combine. The face-fusing feature was used to eliminate overlapping and duplicate faces.

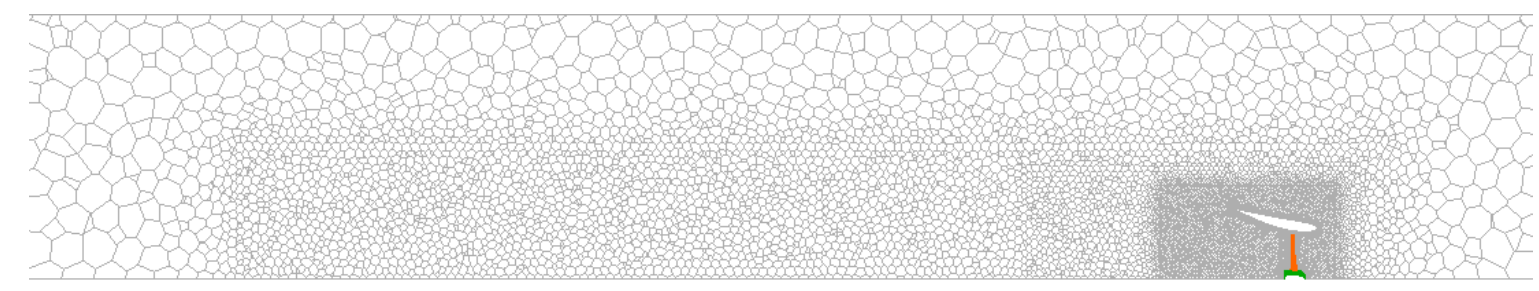

Figure 6. Mesh: Wake refinement.

The average cell size of far wake zone was set at $200 \mathrm{~mm}$. In addition, mesh was refined close to the walls, with great influence on the results, such as blade, hub and diffuser wall, as can be seen in Figure 7. The surface was configured to have 15 inflation layers with an average y+ value of 70 . For the studies of turbine designs with diffuser elements, gap between the blade and diffuser wall is $10 \%$ of the rotor radius (Figure 8). 


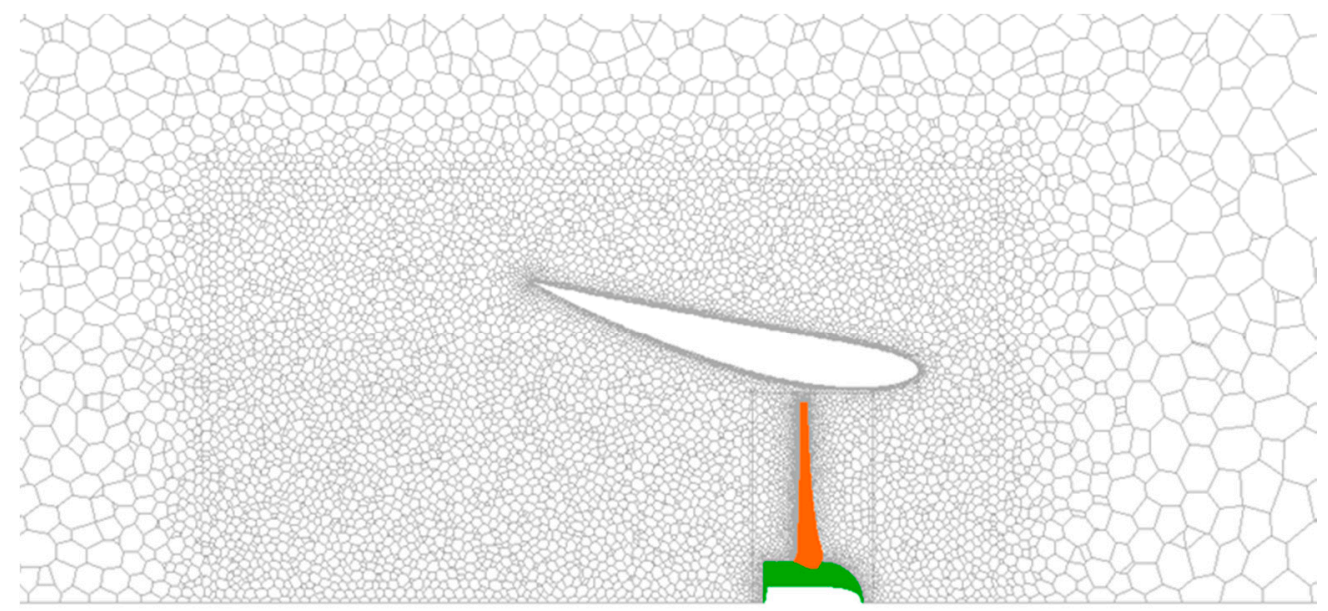

Figure 7. Longitudinal mesh cut.

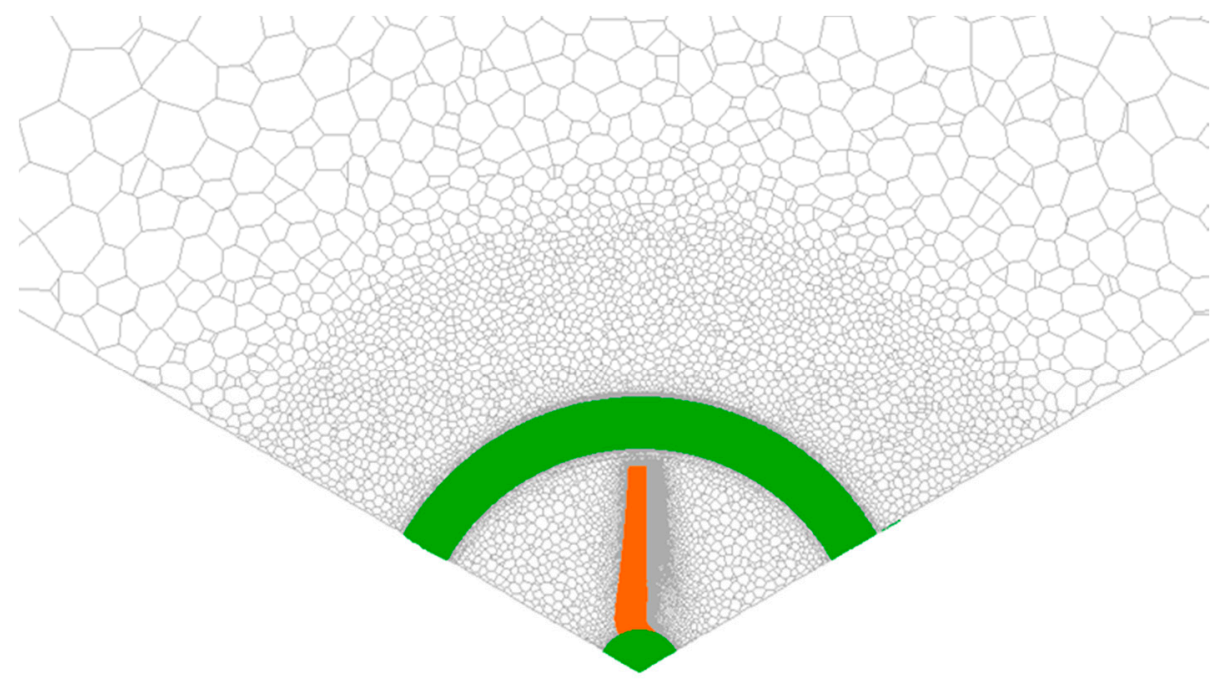

Figure 8. Mesh cut at turbine plane.

\subsection{Numerical Model Validation}

To assure reliable results, the present numerical method and computational procedure were validated by comparison with the experimental data reported in $[10,14]$. The wind turbine with $720 \mathrm{~mm}$ diameter that has three tapered and twisted blades composed of NACA4418 airfoils, was tested in 1440-mm long, 1200-mm wide and 920-mm high wind tunnel. The blade geometry data given in [10] were used to create blade computer-aided design (CAD) model, shown in Figure 9a. The experimental investigations on the performance of $100 \mathrm{~kW}$ tidal current turbines, presented in [14], were carried out in 100-m long, 8-m wide and 3.5-m (with 5-m pit) deep towing tank. The turbine diameter is $700 \mathrm{~mm}$ and each blade consists of 17 sections with NACA 63-418 foil along the whole blade span (Figure 9b). In order to perform CFD simulations, the computational domains were designed using detailed blade geometry data given in $[10,14]$. The power coefficients' comparison was made over a wide range of TSR and results are presented in Figure 10b. 


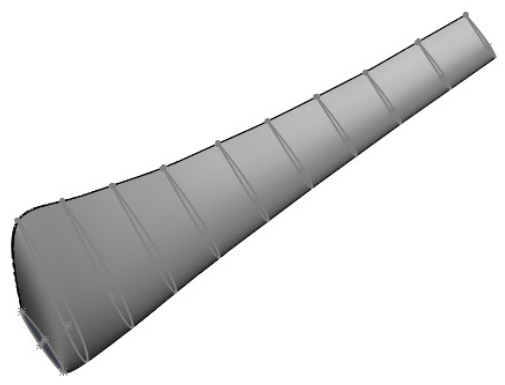

(a)

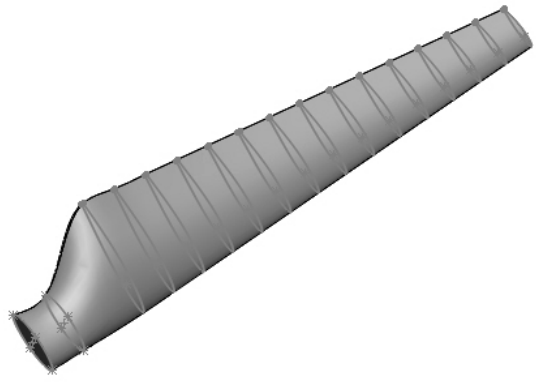

(b)

Figure 9. Designed blade geometries for CFD validation: (a) OPT blade from [10]; (b) Tidal current turbine blade from [14].

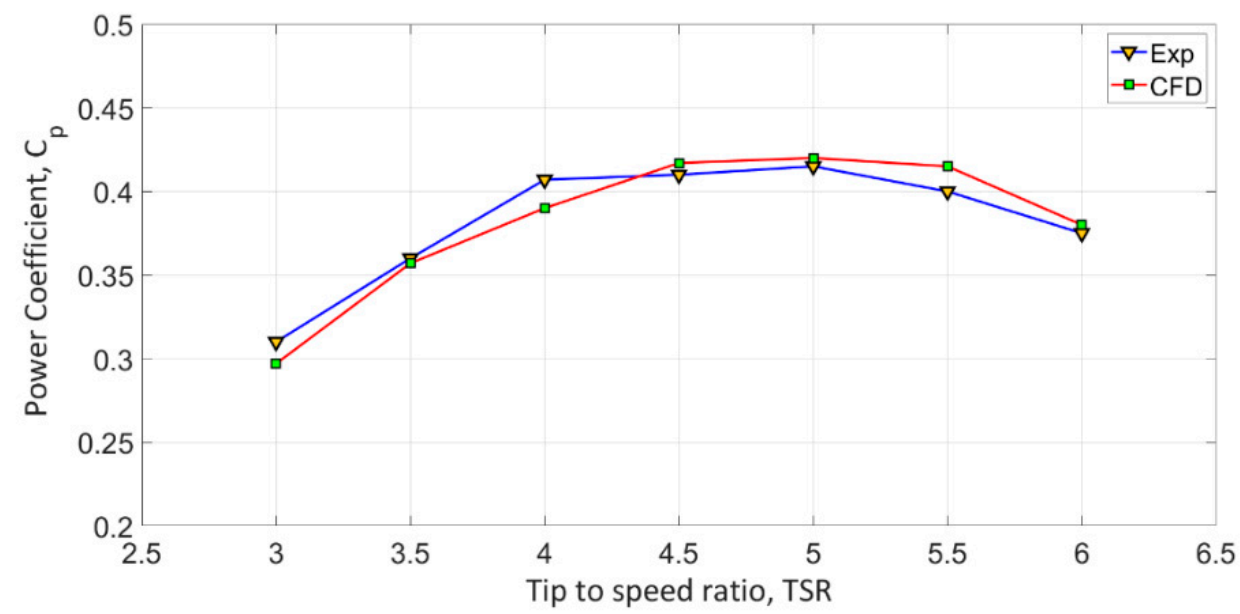

(a)

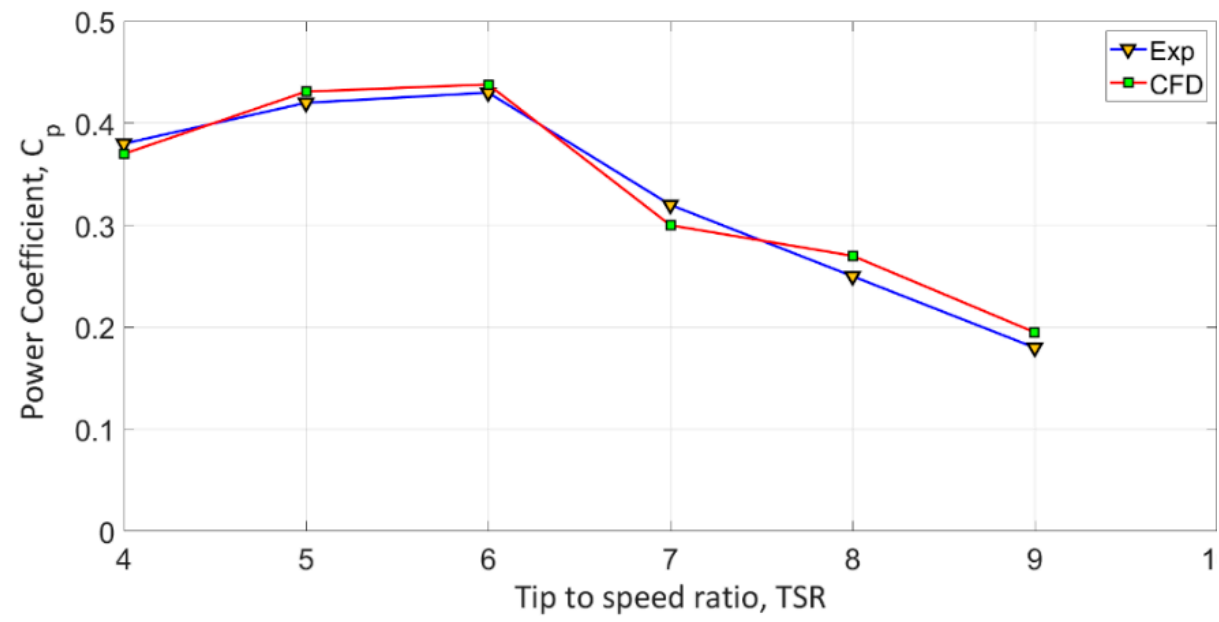

(b)

Figure 10. Comparison between CFD results and experimental data from (a) [10]; (b) [14]. 
Although there are some discrepancies, CFD results achieve good agreement with both experiments, as shown in Figure 10. The comparison with the tidal current turbine experimental data indicate maximum relative error of $8.33 \%$, while the maximum relative error in the case of wind turbine data is $4.13 \%$.

\section{Results}

The comparison of normalized velocity between bare rotor and diffuser-augmented turbine, shown in Figure 11 indicate that maximum axial velocity of the diffuser-augmented turbine is higher than that of the bare turbine.
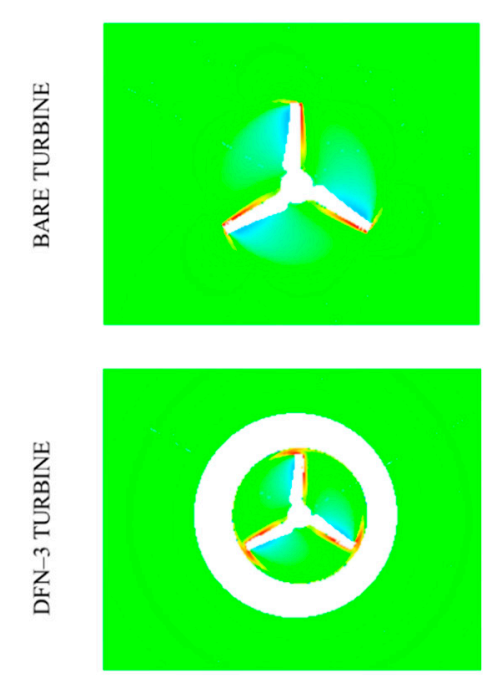

(a)
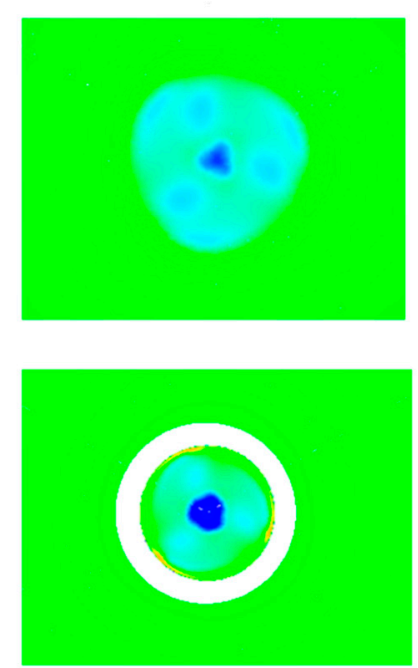

(b)

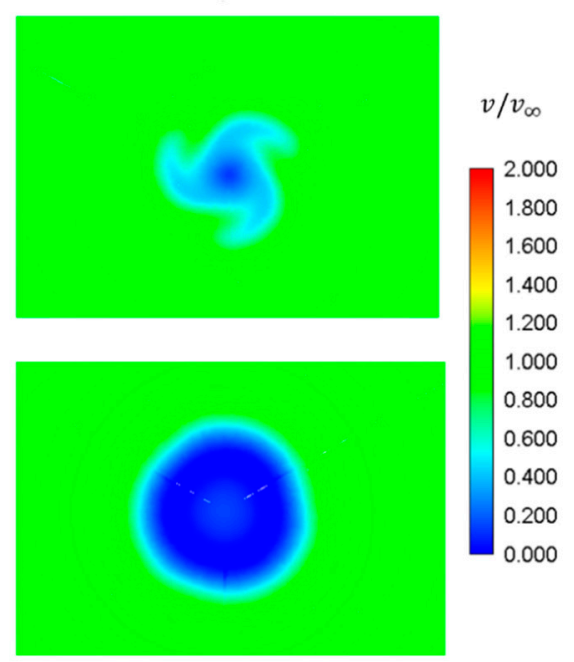

(c)

Figure 11. Normalized velocity at axial distance: (a) 0D; (b) 0.25D; (c) 3D downstream of the hub center.

In the wake region, at 3D far from the hub center, velocity decrease occurs due to formation of recirculation zone, which is even more noticeable in Figure 12. The velocity dissipation and vortex formation behind rotor is predominant in the case of diffuser augmentation. The velocity contours for different diffusers of type DF are presented in Figure 13. It is found that velocity increases at rotor plane with increased open angle and diffuser length. The maximum velocity ratios for the diffuser-augmented turbines were obtained at TSR values of 5, which indicate that optimal values of TSR are shifted. Behind turbine, there is recirculation zone, in which velocity decreases substantially. The wake recovery zone is found to be longer in the case of longer diffusers with higher values of open angle. The lack of wake recovery can have destructive effect on the back-flow turbines in the case of array deployment. In order to avoid reduction of energy extraction capabilities, spacing between diffuser-augmented turbines have to be more than 15D.

Although the highest velocity ratio increase is obtained with brimmed augmentation at TSR value of 5 (Figure 14)), recirculation zone is even longer and spacing between turbines have to be at least 20D. The brim generates a local pressure drop behind it, which creates suction zone and causes velocity increase at rotor plane. There is considerable recirculation zone and vortex formation in the case of brimmed diffuser that is not as strong in the case of other diffuser configurations, as can be seen in Figure 15. 
a)

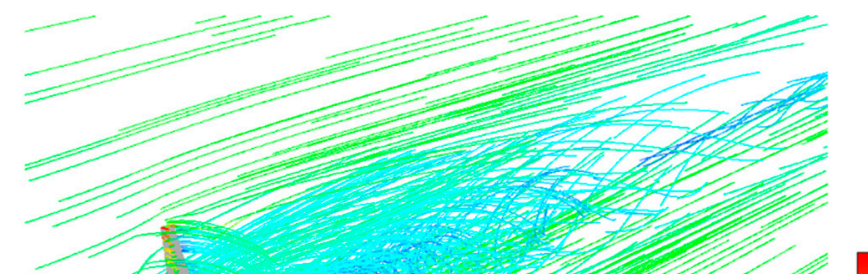
$v / v_{\infty}$

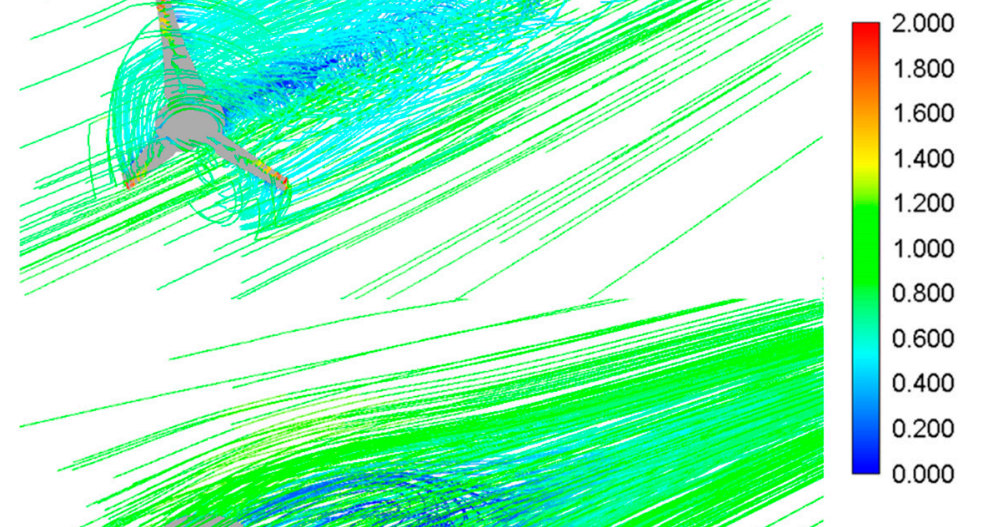

b)

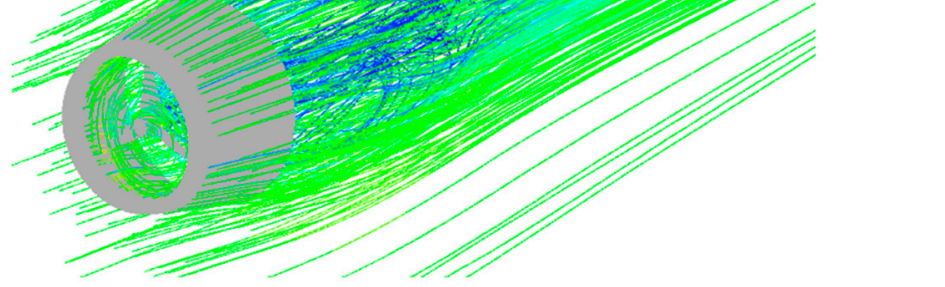

Figure 12. Normalized velocity, 3D streamlines, comparison between: (a) Bare turbine; (b) Diffuseraugmented DFN-3 turbine.

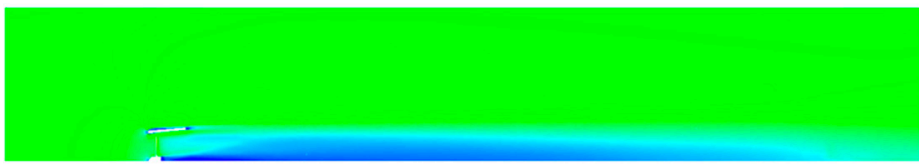

DF-1

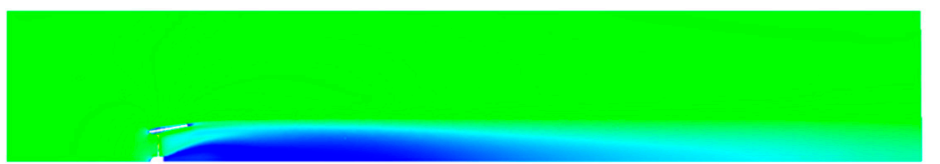

$v / v_{\infty}$

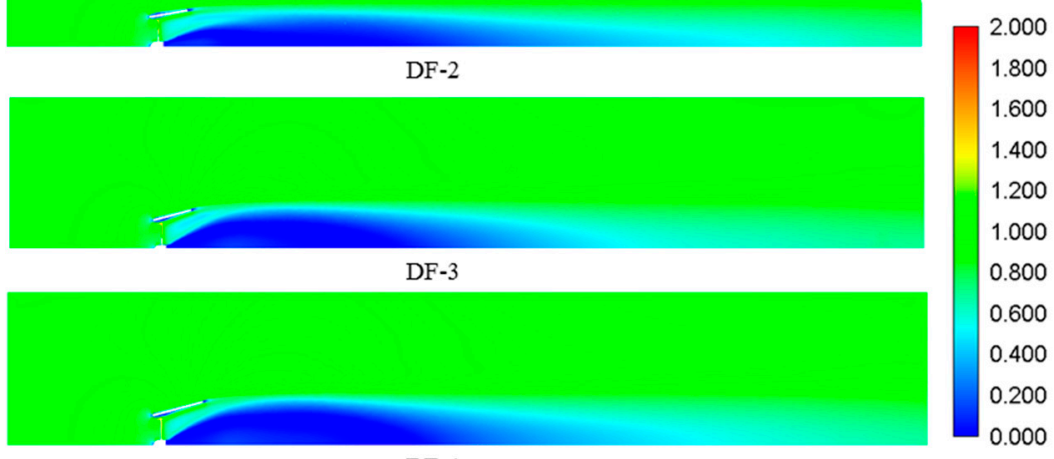

DF-4

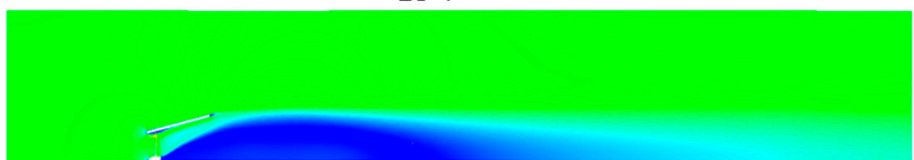

DF-5

Figure 13. Normalized velocity in longitudinal plane at $\mathrm{TSR}=5$, turbine design $\mathrm{DF}$. 


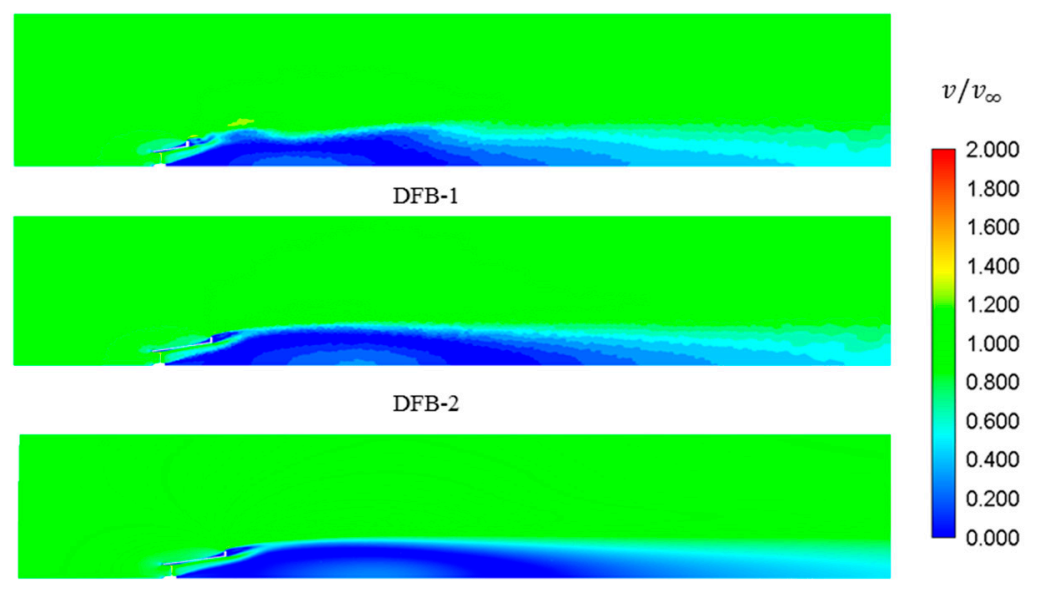

DFB-3

Figure 14. Normalized velocity in longitudinal plane at TSR $=5$, turbine design DFB.

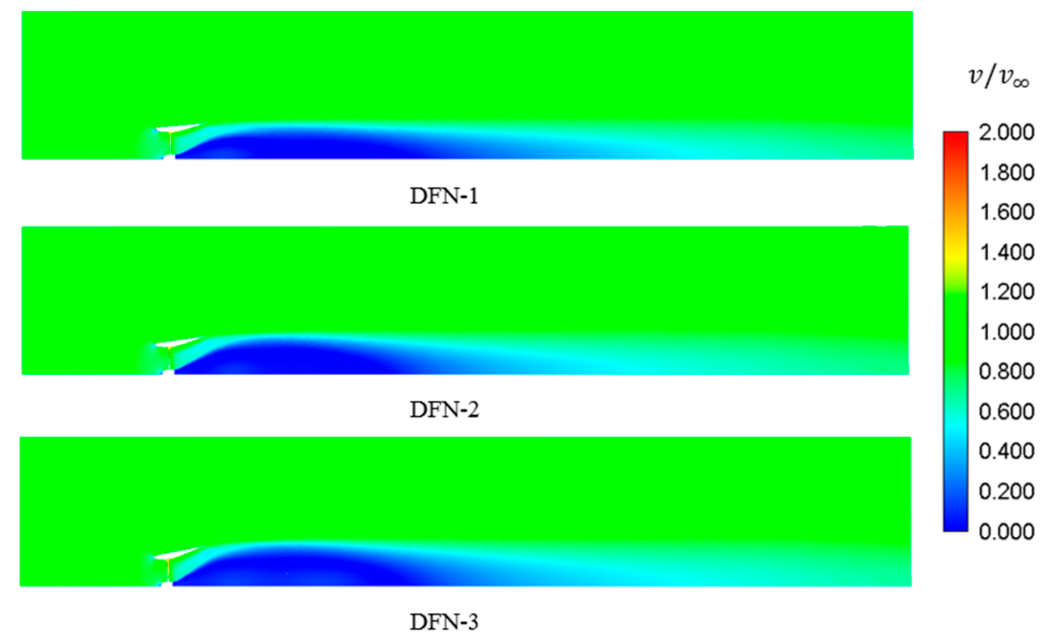

Figure 15. Normalized velocity in longitudinal plane at TSR $=5$, turbine design DFN.

\section{Discussion}

Different turbine design concepts with diffusers were analyzed using three-dimensional CFD and compared with bare turbine over a wide range of TSRs (from 2 to 7). To acquire required TSR number, water velocity was changed from $1.15 \mathrm{~m} / \mathrm{s}$ to $3.25 \mathrm{~m} / \mathrm{s}$ while angular velocity was fixed at $77 \mathrm{rpm}$. The comparison of power coefficients between hydrokinetic turbines with diffusers and the bare turbine is presented in Figure 16. The highest energy conversion efficiency of bare turbine is obtained at TSR $=4$, which is design TSR for the turbine. It is evident that the diffuser can improve energy conversion efficiency even with very simple cross-section geometry over a wide range of operating conditions. However, for more considerable power, augmentation-brimmed diffuser is preferable. In general, increase in diffuser length causes increase in power coefficient, but the stronger impact of diffuser length was observed with simple diffuser designs without brim. For brimmed diffusers, the impact of length increase becomes negligible when diffuser length reaches the value of rotor diameter. It is also important to emphasize that maximum power coefficients of turbines with diffusers were obtained at higher TSR values ( 5 or 6 ). The highest increase in maximum power coefficient is achieved with brimmed diffuser, as can be seen in Figure 17. 


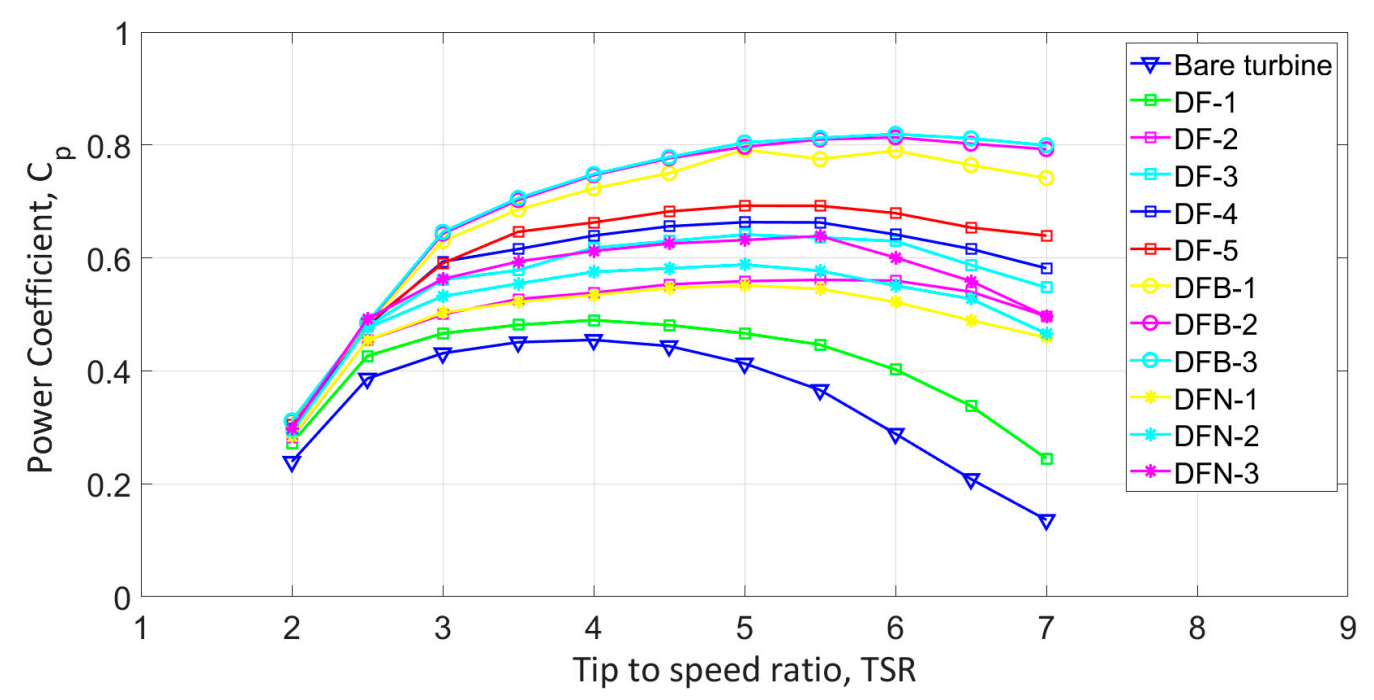

Figure 16. Power coefficients' comparison between bare turbine and turbines with diffusers.

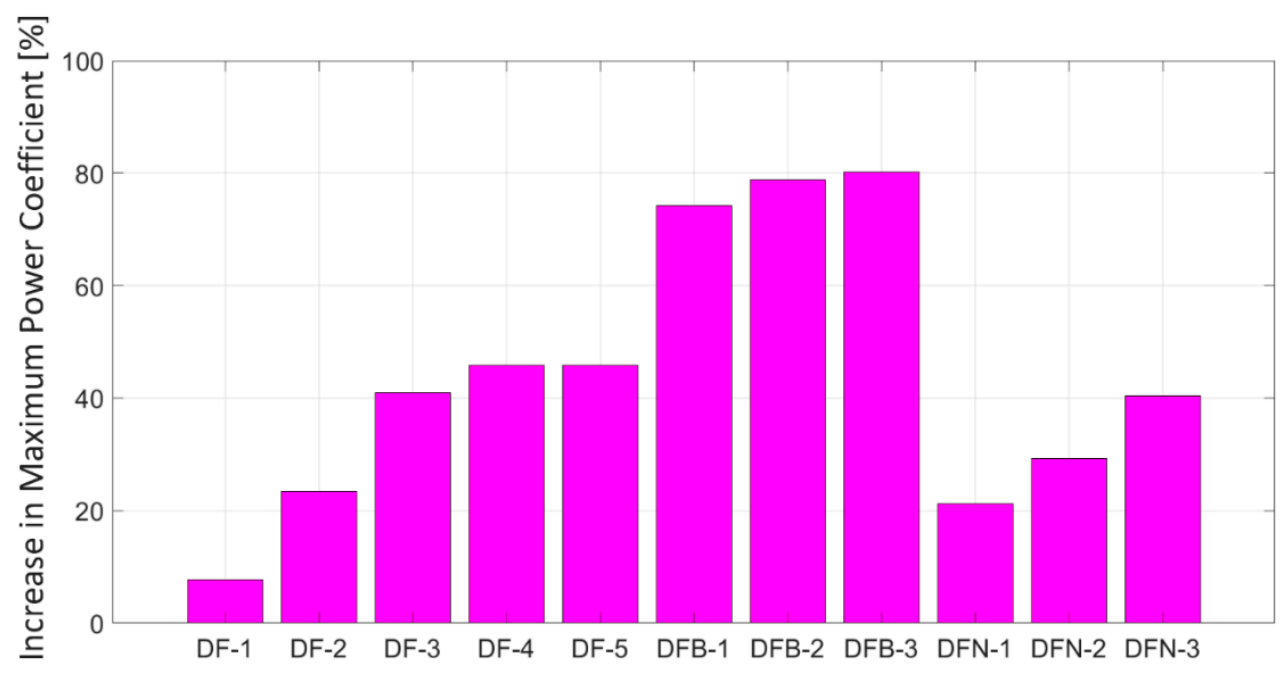

Figure 17. Increase in maximum power coefficient compared to the bare turbine.

The highest percentage rise of $81 \%$ in maximum power coefficient is obtained at TSR value of 5 for turbine design denoted by DFB-3. Similar increase in maximum power coefficient was acquired with turbine DFB-2, which indicates that further increase in diffuser length of brimmed diffuser (above the rotor diameter) is not as effective. Comparison of power coefficients between simple diffuser designs (DF-1-5) and designs with NACA profiles (DFN-1-3) pointed out that the use of larger open angles has far greater impact on power coefficient increase than the use of more sophisticated cross-section profiles, such as NACA profiles. When compared to simple diffuser designs of same dimensions, diffusers with inverted foil cross-section profiles are more effective if diffuser expansion angle is below $10^{\circ}$. In general, water velocity at rotor plane increases as the open angle increases. At higher values of expansion (open) angles (above $15^{\circ}$ ), recirculation or swirl flow is observed at diffuser exit and thus, change in velocity profiles and flow area with further increase in expansion angle is negligible.

This work is a contribution to the better understanding of diffuser augmentation impact on the hydrodynamic performances of micro-hydrokinetic turbines. Results presented can be used as input for further research which should focus on understanding the influence of different brim height and angles on the potential increase in power coefficient. 


\section{Conclusions}

The use of optimization technique in the hydrofoil design procedure can enhance lift coefficient, which leads to higher power coefficient of turbine. The bare rotor turbine which is designed by using the proposed optimization-based approach has a relatively high maximum power coefficient of $45.7 \%$ at TSR of 4. An additional requirement is delayed cavitation inception which has also been included in the optimization of the hydrofoil. To avoid quite complex multi-objective optimization techniques required due to multiple design requirements, the optimization problem was reformulated in the single objective context by prescribing weighting factors to each design objective.

Different diffusers with various geometrical configurations were designed and analyzed from the energy conversion efficiency point of view. Three-dimensional computational fluid dynamics results were obtained using MRF and k- $\omega$ SST models.

It is observed that even with simple diffuser designs, certain increase in the water velocity is obtained. The amount of energy extracted is increased over a wide range of TSR values using diffusers. Energy extraction performances are directly related to the diffuser's geometrical configuration and selected design parameters.

In general, regardless of the turbine configuration, using longer diffusers and higher values of expansion angles results in increased water velocity at rotor plane. More sophisticated cross-section profiles, such as NACA 4412, can improve energy conversion efficiency, but mostly designs with lower expansion angles (below $10^{\circ}$ ). At higher values of expansion angles, performance characteristics are similar to those of designs with simple cross-sections. The results pointed out that configurations with brimmed diffuser are required (DFB design) for more significant energy conversion efficiency improvements. The optimal length of brimmed diffuser with higher open angle is around rotor diameter. Due to separation and recirculation flow, the effect of further increase in diffuser length on the power coefficient is negligible.

Author Contributions: Conceptualization, Z.G. and M.B.; methodology, M.B.; software, Z.G. and M.B.; writing-original draft preparation, M.B.; writing—review and editing, Z.G.; visualization, M.B. All authors have read and agreed to the published version of the manuscript.

Funding: This research received no external funding.

Conflicts of Interest: The authors declare no conflict of interest.

\section{Nomenclature}

\begin{tabular}{|c|c|c|}
\hline & Unit & Description \\
\hline$a$ & - & axial induction factor \\
\hline$a^{\prime}$ & - & angular induction factor \\
\hline B & - & blade number \\
\hline$C_{D}$ & - & drag coefficient \\
\hline$C_{L}$ & - & lift coefficient \\
\hline$C_{p}$ & - & power coefficient \\
\hline$C_{t}$ & - & thrust coefficient \\
\hline $\mathrm{D}$ & $\mathrm{m}$ & diffuser diameter \\
\hline$c$ & $\mathrm{~m}$ & blade chord length \\
\hline$h$ & - & representative mesh size \\
\hline$g$ & $\mathrm{~m} / \mathrm{s}$ & gravitational acceleration \\
\hline$F$ & - & overall correction factor \\
\hline$F_{h}$ & - & hub loss correction factor \\
\hline$F_{t}$ & - & tip loss correction factor \\
\hline$K_{p}$ & - & coefficient of pressure \\
\hline$K_{p_{\text {, min }}}$ & - & minimum coefficient of pressure \\
\hline
\end{tabular}




\begin{tabular}{|c|c|c|}
\hline & Unit & Description \\
\hline$L$ & $\mathrm{~m}$ & diffuser length \\
\hline$N$ & - & total number of mesh cells used for computation \\
\hline$p$ & - & order of convergence \\
\hline$p_{\text {atm }}$ & $\mathrm{Pa}$ & atmospheric pressure \\
\hline$p_{\mathrm{v}}$ & $\mathrm{Pa}$ & vapor pressure \\
\hline$P$ & W & effective power \\
\hline$r$ & $\mathrm{~m}$ & turbine radius \\
\hline$r_{i j}$ & - & grid refinement factor \\
\hline$r_{h}$ & $\mathrm{~m}$ & hub radius \\
\hline$v_{\infty}$ & $\mathrm{m} / \mathrm{s}$ & water velocity \\
\hline$w$ & $\mathrm{~m} / \mathrm{s}$ & relative velocity \\
\hline$w_{1, \alpha=i}$ & - & weighting factors for lift coefficients \\
\hline$w_{2, \alpha=i}$ & - & weighting factors for drag coefficients \\
\hline$w_{3, \alpha=i}$ & - & $\begin{array}{l}\text { weighting factors for minimum coefficients of } \\
\text { pressure }\end{array}$ \\
\hline$T$ & $\mathrm{~N}$ & thrust force \\
\hline$\Delta V_{i}$ & $\mathrm{~m}^{3}$ & volume of the $i$ th cell \\
\hline$\alpha$ & $\circ$ & angle of attack \\
\hline$\alpha_{d}$ & $\circ$ & design angle of attack \\
\hline$\beta$ & $\circ$ & expansion or open angle of diffuser \\
\hline$\theta_{p}$ & $\circ$ & blade pitch angle \\
\hline$\lambda_{r}$ & - & speed ratio at radius $r$ \\
\hline$\varphi$ & $\circ$ & angle of relative flow \\
\hline$\rho$ & $\mathrm{kg} / \mathrm{m}^{3}$ & water density \\
\hline$\sigma$ & - & cavitation number \\
\hline$\omega$ & $\mathrm{rad} / \mathrm{s}$ & turbine rotational speed \\
\hline
\end{tabular}

\section{Acronyms}

$\begin{array}{ll}\text { BEM } & \text { Blade Element Momentum Theory } \\ \text { CAD } & \text { Computer-Aided Design } \\ \text { CFD } & \text { Computational Fluid Dynamics } \\ \text { CNC } & \text { Computer Numerical Control } \\ \text { GCI } & \text { Grid Convergence Index } \\ \text { MRF } & \text { Multiple Reference Frame } \\ \text { RANS } & \text { Reynolds-Averaged Navier-Stokes } \\ \text { TCP } & \text { Tidal Current Power } \\ \text { TSR } & \text { Tip to Speed Ratio }\end{array}$

\section{References}

1. El-Zahaby, A.M.; Kabeel, A.E.; Elsayed, S.S.; Obiaa, M.F. CFD analysis of flow fields for shrouded wind turbine's diffuser with different flange angles. Alex. Eng. J. 2017, 56, 171-179. [CrossRef]

2. Wong, K.H.; Chong, W.T.; Yap, H.T.; Fazlizan, A.; Omar, W.Z.W.; Poh, S.C.; Hsiao, F.B. The design and flow simulation of a power-augmented shroud for urban wind turbine system. Energy Procedia 2014, 61, 1275-1278. [CrossRef]

3. Abdelwaly, M.; El-Batsh, H.; Hanna, M.B. Numerical study for the flow field and power augmentation in a horizontal axis wind turbine. Sustain. Energy Technol. Assess. 2019, 31, 45-253. [CrossRef]

4. Lipian, M.; Dobrev, I.; Karczewski, M.; Massouh, F.; Jozwik, K. Small wind turbine augmentation: Experimental investigations of shrouded- and twin-rotor wind turbine systems. Energy 2019, 186, 115855. [CrossRef]

5. Siavash, N.K.; NajafI, G.; Hashjin, T.T.; Ghobadian, B.; Mahmoodi, E. Mathematical modeling of a horizontal axis shrouded wind turbine. Renew. Energy 2020, 146, 856-866. [CrossRef] 
6. Ghenai, C.; Salameh, T.; Janajreh, I. Modeling and Simulation of Shrouded Horizontal Axis Wind Turbine Using RANS Method. JJMIE 2017, 11, M235-M243.

7. Siavash, N.K.; NajafI, G.; Hashjin, T.T.; Ghobadian, B.; Mahmoodi, E. An innovative variable shroud for micro wind turbines. Renew. Energy 2020, 145, 1061-1072. [CrossRef]

8. Vaz, J.R.P.; Wood, D.H. Aerodynamic optimization of the blades of diffuser-augmented wind turbines. Energy Convers. Manag. 2016, 123, 35-45. [CrossRef]

9. Barbosa, D.L.M.; Vaz, J.R.P.; Figueiredo, S.; Silva, M. An Investigation of a Mathematical Model for the Internal Velocity Profile of Conical Diffusers Applied to DAWTs. Ann. Acad. Bras. Ciênc. 2015, 87, 1133-1148. [CrossRef]

10. Hsiao, F.; Bai, F.; Wen-Tong, C. The Performance Test of Three Different Horizontal Axis Wind Turbine (HAWT) Blade Shapes Using Experimental and Numerical Methods. Energies 2013, 6, 2784-2803. [CrossRef]

11. Wang, Q.Q.; Yin, R.; Yan, Y. Design and prediction hydrodynamic performance of horizontal axis micro-hydrokinetic river turbine. Renew. Energy 2019, 133, 91-102. [CrossRef]

12. Batten, W.M.J.; Bahaj, A.S.; Molland, A.F.; Chaplin, J.R. The prediction of the hydrodynamic performance of marine current turbine. Renew. Energy 2008, 33, 1085-1096. [CrossRef]

13. Liu, H.; Gu, Y.; Lin, Y.; Li, Y.; Li, W.; Zhou, H. Improved Blade Design for Tidal Current Turbines. Energies 2020, 13, 2642. [CrossRef]

14. Song, M.; Kim, M.-C.; Do, I.-R.; Rhee, S.-H.; Lee, J.-H.; Hyun, B.-S. Numerical and experimental investigation on the performance of three newly designed $100 \mathrm{~kW}$-class tidal current turbines. Int. J. Nav. Archit. Ocean Eng. 2012, 4, 241-255. [CrossRef]

15. Chen, W.; Chen, H.; Lin, L.; Yu, Y. Tidal Current Power Resources and Influence of Sea-Level Rise in the Coastal Waters of Kinmen Island, Taiwan. Energies 2020, 10, 652. [CrossRef]

16. Deng, G.; Zhang, Z.; Li, Y.; Liu, H.; Xu, W.; Pan, Y. Prospective of development of large-scale tidal current turbine array: An example numerical investigation of Zhejiang, China. Appl. Energy 2020, 264, 114621. [CrossRef]

17. Sobczak, K.; Obidowski, D.; Reorowicz, P.; Marchewka, M. Numerical Investigations of the Savonius Turbine with Deformable Blades. Energies 2020, 13, 3717. [CrossRef]

18. Rodrigues, S.P.; Brasil, A.P.; Jounior, A.C.P.; Salomon, L.B.R. Modeling of hydrokinetic turbine. In Proceedings of the 19th International Congress of Mechanical Engineering, Brasilia, Brazil, 5-9 November 2007.

19. Knight, B.; Freda, R.; Young, Y.L.; Maki, K. Coupling Numerical Methods and Analytical Models for Ducted Turbines to Evaluate Designs. J. Mar. Sci. Eng. 2018, 6, 43. [CrossRef]

20. Allsop, S.; Peyrard, C.; Thies, P.R.; Boulougouris, E.; Harrison, G.P. Hydrodynamic analysis of a ducted, open centre tidal stream turbine using blade element momentum theory. Ocean Eng. 2017, 141, 531-542. [CrossRef]

21. Silva, P.A.S.F.; Rio Vaz, D.A.T.D.; Brittoa, V.; Oliveira, T.F.; Vaz, J.R.P.; Brasil Junior, A.C.P. A new approach for the design of diffuser-augmented hydro turbines using the blade element momentum. Energy Convers. Manag. 2018, 165, 801-814. [CrossRef]

22. Shives, M.; Crawford, C. Developing an Empirical Model for Ducted Tidal Turbine Performance Using Numerical Simulation Results. Proc. Inst. Mech. Eng. Part A 2012, 226, 112-125. [CrossRef]

23. Tampier, G.; Troncoso, C.; Zilic, F. Numerical analysis of a diffuser-augmented hydrokinetic turbine. Ocean Eng. 2017, 145, 138-147. [CrossRef]

24. Wang, S.; Zhang, Y.; Xie, Y.; Xu, G.; Liu, K.; Zheng, Y. Hydrodynamic Analysis of Horizontal Axis Tidal Current Turbine under the Wave-Current Condition. J. Mar. Sci. Eng. 2020, 8, 562. [CrossRef]

25. Song, K.; Wang, W.; Yan, Y. Numerical and experimental analysis of a diffuser-augmented micro-hydro turbine. Ocean Eng. 2019, 171, 580-602. [CrossRef]

26. Rio Vaz, D.A.T.D.; Vaz, J.R.P.; Silva, A.S.F.P. An approach for the optimization of diffuser-augmented hydrokinetic blades free of cavitation. Energy Sustain. Dev. 2018, 45, 142-149. [CrossRef]

27. Cresswell, N.W.; Ingrama, G.L.; Dominy, R.G. The impact of diffuser augmentation on a tidal stream turbine. Ocean Eng. 2015, 108, 155-163. [CrossRef]

28. Gotelli, C.; Musa, M.; Guala, M.; Escauriaza, C. Experimental and Numerical Investigation of Wake Interactions of Marine Hydrokinetic Turbines. Energies 2019, 12, 3188. [CrossRef]

29. Bai, G.; Li, J.; Fan, P.; Li, G. Numerical investigations of the effects of different arrays on power extractions of horizontal axis tidal current turbines. Renew. Energy 2013, 53, 180-186. [CrossRef] 
30. Belloni, C.S.K.; Willden, R.H.J.; Houlsby, G.T. An investigation of ducted and open-centre tidal turbines employing CFD-embedded BEM. Renew. Energy 2017, 108, 622-634. [CrossRef]

31. Góralczyk, A.; Adamkowski, A. Model of a ducted axial-flow hydrokinetic turbine-Results of experimental and numerical examination. Pol. Marit. Res. 2018, 25, 113-122. [CrossRef]

32. Tian, W.; Mao, Z.; Ding, H. Design, test and numerical simulation of low-speed horizontal axis hydrokinetic turbine. Int. J. Nav. Archit. Ocean Eng. 2018, 10, 782-793. [CrossRef]

33. Riglin, J.; Schleicher, W.C.; Oztekin, A. Numerical analysis of shrouded a micro-kinetic turbine unit. J. Hydraul. Res. 2015, 53, 526-531. [CrossRef]

34. Li, Z.; Zheng, X. Review of design optimization methods for turbomachinery aerodynamics. Prog. Aerosp. Sci. 2017, 93, 1-23. [CrossRef]

35. Manwell, J.F.; Mc, J.G.; Rogers, A.L. Wind energy explained: Theory Design and Application; John Wiley \& Sons Ltd.: Chichester, UK, 2002.

36. Goundar, J.N.M.; Rafiuddin Ahmed, M. Design of horizontal axis tidal current turbine. Appl. Energy 2013, 111, 161-174. [CrossRef]

37. Drela, M.; Youngren, H. Xfoil, Subsonic Airfoil Development System. Available online: http://web.mit.edu/ drela/Public/web/xfoil/ (accessed on 13 June 2020).

38. Selvan, K.M. On the effect of shape parametrization on airfoil shape optimization. Int. J. Res. Eng. Technol. 2015, 4, 123-133.

39. Barbarić, M.; Guzović, Z. Design of hydrofoils for small-scaled hydrokinetic turbines using population-based algorithm. In Proceedings of the 12th Conference on Sustainable Development of Energy, Water and Environment Systems_SDEWES 2017, Dubrovnik, Croatia, 4-8 October 2017.

40. Lain, S.; Contreras, L.T.; Lopez, O. A review on computational fluid dynamics modelling and simulation of horizontal axis hydrokinetic turbines. J. Braz. Soc. Mech. Sci. 2019, 41, 375. [CrossRef]

41. Alfonsi, G. Reynolds-Averaged Navier-Stokes Equations for Turbulence Modelling. Appl. Mech. Rev. 2009, 62, 040802. [CrossRef]

42. ANSYS. ANSYS Fluent Theory Guide; ANSYS Inc.: Canonsburg, PA, USA, 2017.

43. Celik, I.B. Procedure for estimation and reporting of uncertainty due to discretization in CFD applications. J. Fluids Eng. Trans. ASME 2008, 130, 078001.

44. Sosnowski, M.; Gnatowska, R.; Grabowska, K.; Krzywanski, J.; Jamrozik, A. Numerical Analysis of Flow in Building Arrangement: Computational Domain Discretization. Appl. Sci. 2019, 9, 941. [CrossRef]

45. Noruzi, R.; Vahidzadeh, M.; Riasi, A. Design, analysis and predicting hydrokinetic performance of a horizontal marine current axial turbine by consideration of turbine installation depth. Ocean Eng. 2015, 108, 789-798. [CrossRef]

46. Kwaśniewski, L. Application of grid convergence index in FE computation. Bull. Pol. Acad. Sci. Tech. Sci. 2013, 61, 123-128. [CrossRef]

(C) 2020 by the authors. Licensee MDPI, Basel, Switzerland. This article is an open access article distributed under the terms and conditions of the Creative Commons Attribution (CC BY) license (http://creativecommons.org/licenses/by/4.0/). 